\title{
'N BIOLOGIES-GEFUNDEERDE HIPOTESE IN VERBAND MET DIE ONTSTAAN VAN HAKKEL
}

\author{
I.C. UYS B.A. LOG (WITWATERSRAND), M.A. (U.P.)
}

Senior Lektrise: Spraakheelkunde, Universiteit van Pretoria, Pretoria.

\section{OPSOMMING}

'n Kritiese evaluasie van verskeie teorieë, sowel as navorsingsresultate op die gebied van hakkel, dui op baie leemtes, veral met betrekking tot die geheelbeeld van die probleem. Bewys word gelewer dat al die verskillende teorieë alleenlik sekere fasette van die probleem verklaar, maar nie almal nie. Die grootste onduidelikheid is veral gevind ten opsigte van die aanvang van hakkel. 'n Studie van sekere biologiese verskynsels, wat spraak- en taalgedrag ten grondslag lê, lewer 'n moontlike verklaring vir sommige van hierdie onbeantwoorde vrae. Hakkel word beskou as 'n versteuring in ritmiese patroonvorming as 'n temporale verskynsel. Klem word veral gelê op die fisiologiese onvermoë tot tydsberekening in die uiting van lettergr epe. Dit word gesien as 'n onderbreking in die ritmiese vloei van spraak as gevolg van 'n koördinasieaf wyking, inteenstelling met onderbrekings op die supramorfemiese vlak (wat as normale spraak aanvaar word) as gevolg van besluite in verband met die ontwikkeling van sinne. Die hoop word uitgespreek dat hierdie hipotese as stimulus tot eksperimente sal dien.

\section{SUMMARY}

A critical evaluation of different theories and research data in the field of stuttering points to a lack of knowledge as regards many of the salient aspects, particularly in a holistic approach to the problem. Different theories account for only certain facets of the problem, but by no means all of them. The onset of stuttering still remains a riddle. A study of certain biological phenomena underlying speech and language behaviour could yield explanations for some of the unanswered questions. Stuttering is seen as a disturbance in rhythmic patterning, which is a temporal phenomenon. The physiological inability for timing syllable utterance is stressed. This is seen as an interruption in the rhythmic flow of speech due to a disturbance in co-ordination, whereas interruptions at the supramorphemic level (which are accepted as normal speech) are due to decision-making in the generation of sentences. The hope is expressed that this hypothesis may serve as a stimulus for further experimentation.

Gegewens uit Kalamazoo en Illinois dui aaarop dat die voorkomssyfer van hakkel oor die afgelope aantal jare drasties afneem. Daar kom deesdae amper $25 \%$ minder hakkelaars onder die skoolpopulasie voor as omtrent 20 jaar gelede. $^{14}$

Hierdie afname kan waarskynlik toegeskryf word aan die feit dat inligting oor 
die voorkoming en behandeling van hakkel vandag algemeen bekend is. Hakkel word nie vandag meer as 'n slegte, vuil gewoonte beskou nie, maar eerder as "n kliniese probleem.

Maar dit is nie net vir die leek wat daar vandag meer kennis en inligting hieroor beskikbaar is nie. Noukeurige navorsing het daartoe gelei dat wetenskaplike teorieë vandag op navorsingsresultate gebaseer word en baie van die raaiwerk oor hakkel is reeds geëlimineer.

\section{DIE TOESTAND VANDAG}

Onlangs het Van Riper (1971) 'n nuwe boek oor „The Nature of Stuttering"14 die lig laat sien. Hierin is 'n weelde van navorsingsresultate tesame met sy eie ondervinding in verband met hakkel saamgevat.

Hoewel dit nog glad nie die antwoorde op die probleem is nie, lewer 'n deeglike studie van die werk tog 'n baie beter insig op in verband met die aard en probleme van hakkel. Hy kom tot die gevolgtrekking dat daar vandag eintlik nog net ' $n$ antwoord op twee vrae gelewer moet word.

1. Is daar verskillende oorsake wat lei tot verskillende tipes hakkel?

2. Lei die een of ander organies-fisiologiese afwyking tot die aanvang van hakkel? Indien wel, is dit moontlik om die ontwikkeling van verdere sekondêre simptome, neurotiese neigings ens. volgens die leerteorie te verklaar.

Laat ons probeer om ons kennis in verband met beide hierdie aspekte te ontleed.

\section{VERSKILLENDE OORSAKE}

Hoewel Van Riper ${ }^{15}$ hom nie daaraan skuldig maak nie, wil ek graag hakkelgedrag tipeer in ' $n$ poging om verdere riglyne te skep.

Van Riper ${ }^{14}$ stel 4 spore van ontwikkeling voor waar die hakkel by die aanvang, sowel as tydens die ontwikkeling, duidelik van mekaar verskil.

\section{1ste spoor}

Dit kom voor by $\pm 50 \%$ van alle hakkelaars.

\section{Aanvang}

Hakkel begin op die ouderdom van $2 \frac{1}{1} / 2$ jaar. Vlotheid het voorheen voorgekom; dit begin geleidelik; die hakkel kom periodies voor; spraakspoed is normaal; lettergreep-herhalings sonder spanning of tremor kom voor; hakkel kom op die eerste woorde van die sin en op funksiewoorde voor; hy is.onbewus van en nie gefrustreerd oor die onvlotheid nie.

\section{Ontwikkeling}

Herhalings neem toe; spoed word onreëlmatig; herhalings gaan oor in verleng. ings; spanning en tremor kom voor en dit lei tot frustrasie, vrees en vermyding. Dit klink asof hierdie tipe ooreenstem met die idee van aangeleerde gedrag, waar die kind moontlik gediagnoseer is en die semantogeniese invloede gelei het tot die ontwikkeling van hakkel (verg. Johnson). 


\section{2de spoor}

Dit omvat $\pm 25 \%$ van alle hakkelaars.

Aanvang

Hakkel begin laat; vlotheid kom nooit voor nie; dit begin geleidelik; artikulasie is swak; spraakspoed is vinnig (uitbarstings); hersiening, gapings en herhalings kom voor sonder tremor of spanning; hakkel kom meestal op eerste woorde, inhoudswoorde en langwoorde deur die hele sin voor; die patroon varieer; die spraak is gefragmenteer selfs tydens vlot periodes; geen bewustheid, frustrasie of vrees kom voor nie.

Ontwikkeling

Spraakspoed neem toe; min verandering tree in; duur van onvlotheid neem toe; soms kom vrees vir situasies voor (nie vir woorde en klanke nie); oog-kontak is goed; hy steek nie die hakkel weg nie; hakkel bly primêr herhalend; spraak is ongeorganiseerd.

Hierdie tipe stem baie duidelik ooreen met stamel omdat die idee van ongeorganiseerdheid, tesame met vinnige herhalende tipe spraak waarvan die spreker redelik onbewus bly, sinvol gekoppel kan word aan die beeld van die stamelaar. Dit kan ook verklaar waarom daar nie tydens die ontwikkeling 'n merkbare toename in die erns van die probleem is nie (verg. Weiss ${ }^{16}$ ).

\section{3de spoor}

Dit omvat $\pm 12 \%$ van alle hakkelaars.

\section{Aanvang}

Die hakkel kan op enige stadium na die aanname van taal begin; vlotheid het voorheen voorgekom; begin dikwels na 'n skielike trouma; artikulasie is normaal; spraakspoed is stadig en versigtig; stemlose verlengings kom voor; laringeale afbrekings kom voor; daar is baie spanning en tremors; die patroon bly konstant; normale spraak is vlot; hy is baie bewus van die probleem, is bevrees en gefrustreèrd.

\section{Ontwikkeling}

Toename in frekwensie en frustrasie; begin spraakpogings oor; fiksasies van orale strukture en verlengings en bewing kom voor; worstelreaksies word waargeneem; spraakspoed neem af; hy weier om te praat en vermy; oogkontak is swak; stemlose toniese afbrekings met veelvuldige sluitings kom voor.

Die simptomatologiese beeld vanaf die aanvang by hierdie tipe herinner baie aan die een of ander organiese probleem, meer spesifiek 'n moontlike betrokkenheid van die ekstrapiramidale bane (insluitend die Corpus striatum) wat kan lei tot 'n vorm van disartrie. 
4 de spoor

Omvat $\pm 12 \%$ van alle hakkelaars.

Aanvang

Hakkel begin laat - gewoonlik na 4 jaar; vlotheid het voorheen voorgekom; die aanvang is skielik; artikulasie is normaal; spanning en tremor kom voor; hy hakkel op inhoudswoorde; die patroon is konstant; hy is bewus van die probleem, maar nie gefrustreerd nie.

Ontwikkeling

Hakkel neem toe; dit is monosimptomaties en simbolies; woordvrese kom nie voor nie en vermyding is min; hy is baie bewus van die probleem, maar hakkel openlik; oogkontak bly goed en hy praat baie; patroon bly oor die algemeen baie stabiel.

"They watch you as you react to it. And they are rarely emotional about it". ${ }^{14}$

As gevolg van die kenmerkende laat aanvang, en die onderskeidende simptome, veral die feit dat hy bewus is van, maar nie negatief op die simptome reageer nie, klink dit na 'n tipe hakkel wat sal inpas by 'n neurotiese teorie. (verg. Barbara ${ }^{1}$ ).

Aangesien die idee van hierdie 4 spore van ontwikkeling gegrond is op 'n deeglike studie van talle hakkelaars oor baie jare, is dit aanvaarbaar. Die groot leemte van 'n teorie gebaseer op verskillende oorsake van verskillende tipes hakkel, lê egter opgesluit in die gebrek aan verklaring van alle verskillende fasette van die hakkelprobleem. Ons kan egter nie een van die teorieë summier verwerp nie, omdat daar, wat sekere aspekte betref, 'n waardevolle bydrae deur elk gelewer is.

\section{'N EVALUASIE VAN DIE TEORIEË N.A. V. NA VORSINGSR'ESULTATE}

\section{Hakkel as aangeleerde gedrag}

Hakkel word vandag deur meeste gedragsielkundiges soos volg gesien: ${ }^{7}$

Die oorspronklike hakkelmomente word geproduseer deur 'n onaangename emosionele ontwrigting en die hakkel verteenwoordig onderbrekings en disorganisasie van normale spraak. ${ }^{6}$ Dit vind plaas a.g.v. klassieke kondisionering (respondent learning) wat verbind kan word met die werking van die outonome senuweestelsel. Operante kondisionering tree in werking (deur die sentrale senuweestelsel) in die ontwikkeling van sekondêre simptome.

Daar is egter 'n paar stellings in verband met hakkel as aangeleerde gedrag wat nadere beskouing verg:

1. Hakkel ontstaan onder toestande van negatiewe emosie. Hoewel navorsingsresultate nog onvoldoende is, bewys studies dat dit baie selde die geval is.

2. Negatiewe emosie vererger normale onvlotheid. Navorsingsresultate is tot so 'n mate weersprekend dat geen geldige afleidings daarop gebaseer kan word nie. 
3. Hakkel kan gekoppel word aan voorafgaande stimuli. Ons kan alleenlik aflei dat verwagting in die geval van volwassenes wel 'n rol speel. ${ }^{17}$

4. Straf kan hakkel laat afneem of toeneem. Redelik uitvoerige navorsing bewys dat beide moontlik is.

5. Positiewe versterking laat hakkel toeneem. Daar is baie min bewyse om hierdie hipotese te ondersteun.

6. Negatiewe versterking laat hakkel toeneem. Dit is wel bewys.

7. Hakkel is selfversterkend.

Die vreesvermindering wat voorkom tydens hakkel, versterk moontlik die gedrag, maar geen besliste bewyse is nog gevind nie.

Hoewel ons dus op hierdie stadium kan sê dat klassieke en operante kondisionering sekere aspekte van hakkelgedrag verklaar, vereis die kerngedrag (veral die aanvang) 'n ander verduideliking. Die leerteorie verklaar redelik bevredigend die ontwikkeling van hakkel; maar glad nie die ontstaan nie.

\section{Hakkel as die sekondêre' gevolg van stamel}

Volgens Weiss (1964) is stamel ,.... the mother lode of stuttering". 16

Hierdie teorie word gegrond op twee verskynsels.

i. In meeste gevalle word hakkel voorafgegaan deur 'n periode van maklike herhalings, verlengings, huiwerings en selfkorreksies. Wanneer dit gepaardgaan met 'n sterk aanduiding van oorerwing, beskou Freund ${ }^{8}$ dit as stamel. Dit spruit daaruit dat die dryfkrag tot spraak groter is as die kapasiteit tot ekspressie.

ii. Nadat die hakkelaar gerehabiliteer is, bly daar nog sekere onvlothede in sy spraak oor, wat weer eens ooreenstem met en dus beskou kan word as stamel.

Een van die sterkste punte van hierdie teorie is die feit dat Stromsta bewys het dat die normale onvlothede van die jong kind wat later begin hakkel het, wel verskil van die kind wat nie in 'n hakkelaar ontwikkel het nie. Die moontlikheid bestaan dus wel dat daardie simptome as stamel beskou kan word.

Ongelukkig verklaar hierdie teorie nie die ontstaan van alle vorms van hakkel nie. ${ }^{8}$ Nog 'n leemte is dat hierdie teorie 'n sekere persoonlikheidstipe aanvaar wat daartoe sal lei dat sekere stamelaars in hakkelaars sal verander. ${ }^{8,9}$ Navorsingsbewyse is nog nodig voor hierdie hipotese aanvaar kan word.

\section{Hakkel as 'n organiese afwyking}

Daar is iets in die indruk wat die hakkelaar skep wat mens laat wonder of daar nie tog die een of ander organiese probleem is nie.

Navorsing i.v.m. lateraliteit, genetiese faktore, die kardiovaskulêre stelsel, metabolisme, die senuweestelsel ens., lewer in so 'n mate positiewe resultate op dat dit lyk asof 'n organiese teorie tog nie verwerp kan word nie.

Onlangse navorsing dui veral op die volgende moontlikhede:

1. dat onvolledige serebrale dominansie of bilaterale spraakverteenwoordiging 
in verband staan met hakkel (verwys Jones ${ }^{2}$ );

2. dat hakkel wel gekoppel kan word aan 'n familiële probleem;

3. dat daar ' $n$ verband is tussen hakkel en allergiese toestande;

4. dat asemhalingsversteurings en spraakspoedversteurings nie net die gevolg van hakkel is nie;

5. dat daar aanduidings van 'n minimale versteuring in die sentrale senuweestelsel by hakkel teenwoordig is.

Die grootste leemte op hierdie gebied is egter myns insiens die feit dat 'n massa gegewens oor beperkte aspekte van dié omvattende probleem ons visie in verband met die totale beeld vertroebel.

In teenstelling hiermee is dit egter weer moontlik om volgens die neurokubernetika baie van die ander teorieë te omskryf en te verklaar. So bv. kan Sheehan $^{12}$ se teorie i.v.m. die toenaderings- en vermydingsdryfkragte verklaar word volgens elektromiografiese bevindings i.v.m. die ooreenstemming van bewegingsfases en spierspanning.

\section{'N BIOLOGIESE GRONDSLAG}

In 'n poging om' 'n organies-fisiologiese basis vir die aanvang en kerngedrag van hakkel te soek, is dit miskien sinvol om te begin by 'n hipotetiese teorie wat op grond van bekende biologiese feite verdedigbaar is.

As uitgangspunt kan die volgende hipotese gestel word:

dat hakkel primêr ' $n$ afwyking in die temporale aspekte van spraak is a.g.v. ' $n$ biologiese onvermoë om die motoriese opeenvolging van gegewe klanke, lettergrepe of woorde op die aanvaarde of vereiste momente in tyd te bemeester.

Motivering en verdediging

Die voordeel van 'n definisie van hakkelgedrag is, dat

1. die basiese aard van die probleem waargeneem kan word;

2. die aantal afbrekings getel kan word om die erns vas te stel;

3. die gedrag wat gemodifiseer moet word, vasgepen kan word.

Dit is aanvaarbaar dat daar graadverskille bestaan tussen die onvlotheid van nie-hakkelaars en hakkelaars. Navorsingsresultate dui op die volgende: ${ }^{14,2}$

1. Hakkelaars toon meer intrawoord-onvlothede.

2. Hakkelaars toon meer verlengings van klanke en herhalings van lettergrepe en woorde.

3. Van alle onvlothede is woorddeel-herhalings makliker diagnoseerbaár as hakkel, terwyl invoegings, hersienings en frase-herhalings eerder as normaal beskou word.

4. Die erns van die hakkel word bepaal deur hoeveelheid
a. lettergreep- of klankherhalings;
b. klankverlengings;
c. gebreekte woorde;
d. ongewone klem of spanning. 
Na aanleiding van bg. bevindings definieer Van Riper (1971) hakkel as volg: ,.... a stuttering behavior consists of a word improperly patterned in time and the speaker's reaction thereto". 14

Wanneer ' $n$ hakkelspasma voorkom, word die temporale eenheid van die motoriese patroon verbreek as gevolg van tydsdistorsies in die komponente klanke of lettergrepe waaruit die woord bestaan, bv. herhalings, verlengings, gapings en/of invoegings van ander ontoepaslike gedrag.

Spraak word beide motories en akoesties in tyd gerangskik - die bewegings, klanke en lettergrepe moet in 'n voorgeskrewe volgorde voorkom. Wanneer hierdie opeenvolging in spraakuiting merkbaar verbreek word, en dit as onaanvaarbaar bestempel word, kan dit gesê word dat die persoon hakkel. Hakkel is dus ' $n$ afwyking in die tydsberekening en -besteding.

Hierby is betrokke 'n temporale verbreking van die gelyktydige en opeenvol. gende programmerings van spierbewegings wat 'n voorvereiste is vir die produksie van óf een van die woord se geīntegreerde klanke, óf een van die lettergrepe, óf die presiese koppeling van klanke en lettergrepe waaruit die spesifieke motoriese patroon bestaan. Dit is in werklikheid die kerngedrag in hakkel.

Dit is egter nog nodig om ter verdediging van hierdie stellings die volgende vas te stel:

1. Die hoeveelheid temporale verbreking;

2. die strukture daarby betrokke;

3. die oorsprong van die asinchronie.

Alle gedrag is ' $n$ integrale deel van die mens se konstitusie; dit is 'n integrale deel van die organiese geheel; dit is verwant aan struktuur en funksie, waar die een die ekspressie van die ander is. Gedrag het dieselfde geskiedenis en oorsprong as bv. liggaamsvorm en fisiologiese funksies.

Met verwysing na die werke van Luria, ${ }^{11}$ om maar een te noem, kan ons aanvaar dat gedrag (en hier meer spesifiek spraak en motoriese koördinasie) gereguleer word deur'n sentrale beheermeganisme. Die vloeiende uitvoering van enige beweging vereis sinergistiese interaksie van 'n aanșienlike hoeveelheid spiere. Oor die algemeen produseer ' $n$ mens \pm 220 lettergrepe per minuut (huiwerings en pouses ingeslote). Dit is dus aanneemlik dat van 10 000-15000 neuromuskulêre veranderinge per minuut kan plaasvind. Die kwessie van tydsberekening en -besteding in spraakgedrag mag nie onderskat word nie. Eksperimente het bewys dat waar 'n melodie as stimulus aangebied word, variasies in toonhoogte, luidheid en kwaliteit geëlimineer kan word sonder om herkenning te laat skade ly. Die melodie word alleenlik onherkenbaar wanneer die interne temporale verhoudings vernietig word.

Die essensiële aard van 'n tydspatroon is 'n onderliggende pols of slag - d.i. ritme. Die ritme onderliggend aan spraak blyk gebaseer te wees op ritmiese wisselings tussen stadiums of toestande. So bv. is daar stadiums van inisiasie en uitvoering van motoriese patrone (siklusse van aktivering en inhibisie). Navorsing dui daarop dat hierdie tipe spraakpatroonvorming in tyd gebaseer is op 'n onderliggende ritmiese metriek: (Volgens Van Riper ${ }^{14}$ is hierdie navorsingresultate van belang) . 
1. Stetson beskou die letterg̈reep as die ware basiese eenheid van spraak. Dit bepaal in ' $n$ groot mate die spraakr itme. Die fisiologiese korrelaat is die asempols. Hy vind dat, aangesien meeste lettergrepe uit 'n vokaalkern met konsonantgrense of stilte bestaan, die konsonante die lugvloei vertraag of stop. Dit veroorsaak hindernisse in die vloeiende sametrekking van die torakswande. $\mathrm{Na}$ aanleiding hiervan is toe vasgestel dat die asempolse rondom \pm 6 per sekonde sentreer.

2. Hudgins e.a. vind dat die relatiewe spoed van artikulasiebewegings vir die uitspraak van onsin-lettergrepe soos „ta-ta-ta" sentreer romdom 5,5-7,5 per sekonde.

3. Lenneberg vind dat selfs sekere denkprosesse hiermee ooreenstem. Wanneer mens in die gedagte so vinnig as moontlik tel, kan 'n spoed van omtrent 6 per sekonde gehandhaaf word.

4. Brazier het onlangs interessante bevindings i.v.m. E.E.G.-resultate gepubliseer. Hy vind dat daar oor die temporopariëtale gedeeltes 'n basiese ritme van 7 siklusse per sekonde voorkom. Hy bemerk dat kinders nie spraak en taal aanleer voordat 'n sekere mate van elektrofisiologiese rypheid ont. wikkel het nie. Hy definieer dit in terme van 'n toename in die frekwensie van hierdie dominante ritme wat met ouderdom vasgestel word.

5. Molina e.a. merk op dat met elektriese stimulasie van die talamus, spraak versnel kan word. Hulle vind dat die vinnigste wat die persoon kan praat (in hierdie geval tel) \pm 170 millisekondes per telling is. Dit stem ooreen met \pm 6 per sekonde.

6. Black vind in verband met die Lee-effek dat daar 'n sekere kritiese vertraging is wat maksimale spraakontwrigting meebring, nl. $2 / 11$ sek., of anders gestel, $\pm 1 / 6$ van 'n sekonde. ${ }^{4,13}$

7. Cherry en Taylor het in eksperimente met digotiese gehoor ook interessante bevindings gemaak. Persone is gevra om sinne te herhaal nadat hulle dit gehoor het. Die sein is toe reëlmatig tussen die linker- en regteroor gewissel. Hulle vind dat indien die oorskakelingspoed redelik stadig is, die persoon genoeg inligting links en regs ontvang om die sin met gemak te herhaal. Wanneer die oorskakelingspoed te vinnig is, makk die persoon staat op die dominante oor om sodoende die stimulus van die nie-dominante kant in te vul. Hulle beskou die kritiese oorskakelingspoed, wat spraakbegrip en -weergawe die meeste belemmer, as een keer elke 1/6 sekonde. Hulle lei dus af dat 'n spraaksein die meeste deur hierdie spoed afgetakel word. ${ }^{10}$

Met inagneming van bogenoemde navorsingsresultate kan die hipotese dus gestel word dat temporale patrone vir spraak, waarop neuromuskulêre outomatismes gebaseer is, 'n fisiologiese ritme van veranderinge van toestande openbaar $\mathrm{nl}$. siklusse van \pm 6 per sekonde.

\section{Ritme en hakkel}

Heelwat navorsing is al gedoen in verband met ritme en hakkel, waar 'n positiewe verband vasgestel kon word. 
Die ritme-effek

Dit is bewys dat die invoering van 'n definitiewe ritme hakkel verhoed of onderdruk, bv. spraak saam met die tik van 'n metronoom. Resultate dui daarop dat ' $n$ onreëlmatige tik nie die effek het om vlotheid te versterk nie. Hoewel ek geen definitiewe aanduidings in die literatuur kon vind nie, behoort dit interessant te wees om te weet watter metronoomspoed vlotheid maksimaal sal stimuleer. Indien in ag geneem word dat hierdie tipe stimulasie tydsberekening van motoriese patrone fasiliteer, kan dit nie summier verwerp word as 'n afleidingsmeganisme nie. Van Riper dui tereg daarop dat oordrag na gebruik van hierdie tegniek swak is, omdat spraak nie reëlmatig ritmies is nie. Faktore soos emosie, kommunikasietoestande ens. sal 'n invloed op ritmespoed uitoefen.

\section{Tydsberekeningsmeganismes in hakkel}

Kliniese waarneming bewys dat tydsberekening 'n belangrike faktor is in die voorkoms van hakkel. So bvi beinvloed tydsdruk die hakkelaar se spraak. Verskeie van die hakkelaar se simptome kan geïnterpreteer word as soekende gedrag - gedrag wat daarop gerig is om die regte tydsberekening vir die uiting van 'n woord te bewerkstellig. Wanneer sekondêre simptome soos kopruk, spiersametrekkings ens. ondersoek word, sal gevind word dat dit ballistiese bewegings is wat die ontsnapping uit 'n toestand van fiksasie bewerkstellig. Weer eens is met elektromiografiese navorsing gevind dat tydsberekening 'n belangrike rol speel. ${ }^{14}$ Alleenlik wanneer hierdie skielike beweging uit fase is met die tremor, sal ontsnapping moontlik wees.

\section{Terapeutiese tydsberekeningsmetodes}

Verskeie metodes wat al met sukses aangewend is in terapie, kan beskou word as metodes waardeur die hakkelaar gehelp word met tydsberekening vir sy spraakpogings. Hier kan genoem word, Froeschels se koumetode, Travis en Bryngelson se metode waardeur die hakkelaar aangemoedig word om te praat terwyl hy skryf en selfs Johnson se bonsmetode.

\section{Koorlees en skaduspraak}

Wanneer die terapeut en die hakkelaar saam lees dien die terapeut se spraakuiting as bykomende tydsein waardeur tydsberekening in die geval van die hakkelaar se uiting gefasiliteer sal word. Min of meer dieselfde proses vind plaas in die geval van skaduspraak waar die terapeut eers die woord sê en die hakkelaar dit dan vlot herhaal. Hy het weer eens vooraf 'n voorbeeld van tydsberekening en spraakritme gekry. 5,14

\section{$\underline{\text { Sang }}$}

Nadoleczny, Johnson e.a. vind dat minder as 10\% hakkelaars onvlot is tydens sang. Wingate mak die stelling dat, in teenstelling met metronoomspraak, dit nie die gereeldheid van ritmiese polse in sang is wat tot vlotheid lei nie, maar eerder ' $n$ faktor betrokke by tydsberekening en intonasie. Ons weet ook dat daar ' $n$ baie noue verwantskap tussen intonasiekontoere en spraakritme bestaan. ${ }^{14}$ 


\section{Adaptasie}

Agnello vind dat hakkelaars in die besonder probleme ondervind met die oorgange wat nodig is in die uiting van snelsêers (tongue twisters). In verband hiermee merk Wingate op dat by die herhaalde lees van dieselfde stuk, die hakkelaar ' $n$ verbetering toon in die tydsberekening vir motoriese koördinasiepatrone. Ter bevestiging van hierdie stelling, vind Besozzi en Adams ${ }^{3}$ dat die adaptasie-effek duideliker warneembaar is wanneer die persoon die stuk elke keer hardop lees. Adaptasie neem af wanneer stillees soms toegelaat word.

\section{Neurologiese ritme}

Lindsley en Stromsta ${ }^{14}$, vind dat bilaterale E.E.G.-opnames van nie-hakkelaars toon 'n groter mate van gesinchroniseerdheid as dié van hakkelaars. Elektromiografiese studies deur Travis ${ }^{14}$ dui weer aan dat aksiepotensiale van die maseterspiere bilaterale wanverhoudings in aankomstye tydens hakkel toon, wat nie voorkom tydens vlot spraak nie.

Studies deur Chevrie-Muller lewer ook bewys van asinchronie in stemlipfunksie by hakkelaars. ${ }^{14}$

Hoewel hierdie studies nog nie afdoende bewyse van al die verskillende fasette lewer nie, mag die aanduidings daaruit verkry nie onderskat word nie.

\section{AFLEIDING}

Om terug te keer tot Van Riper ${ }^{14}$ se definisie van hakkel, m.b.t. ,... . a word improperly patterned in time ....". is daar sekere feite aan die lig gebring wat daarop dui dat dit eerder 'n geval is van ,,. a svllable improperly patterned in time ...." Wanneer verwys word na studies i.v.m. die diagnose van hakkel deur luisteraars, is dit duidelik dat die sterkste gereageer word op verbreking van die lettergreep.

„Not all of the interruptions to the forward flow of speech are signs of stuttering". , . . . of all the types of disfluency, part word repetitions are more likely to be classified by listeners .... as 'stuttering' and that certain other kinds of disfluency, most notably perhaps interjections, revisions, and phrase repetitions, are more commonly considered as "normal' disfluencies". 14 'n Verklaring hiervoor kan gevind word in 'n studie van die aanname van spraak en taal by die kind, normale onvlotheid en die aanvang van hakkel. Volgens Van Riper ${ }^{14}$ leer die kind woorde as motoriese eenheidspatrońe. Dit is miskien meer korrek om te sê dat die kind spraak op die morfemiese vlak as eenheidspatrone aanneem. Elke opeenvolgende benadering word gemodifiseer tot die produk kommunikatief aanvaarbaar is, m.a.w., bekende motoriese patrone word omvorm en gefatsoeneer (shaped) en dit vereis terugvoering. Hierdie patrone word dan gestabiliseer, afhangende van oefening, terugvoering en die kompleksiteit van die koördinasie.

Van Riper ${ }^{14}$ meen dat stabiliteit in 'n hierargiese volgorde, verdeel kan word nl. die klankvlak, lettergreepvlak, woordvlak en sinvlak, waar die klankvlak' die meeste stabiel sal wees en die sinvlak die minste stabiel. 
Weer eens kan daarop gedui word dat die morfemiese vlak meer stabiel sal wees as die supramorfemiese vlak. Meeste woorde val buite die grense van die morfemiese vlak. Dus kan meeste woorde ook met reg beskou word as supramorfemiese strukture, tesame met die frase en die sin, omdat dit gedurig gegenereer word.

In die normale onvlotheidsperiode kom afbrekings op die supramorfemiese vlak dikwels voor. Hierdie ongeorganiseerde vorm van spraak word meestal deur luisteraars as anneembaar beskou in die spraak van kinders, en volwassenes, juis omdat dit ' $n$ funksie van besluite is wat nog geneem moet word. Gedisorganiseerde spraak kan herken word aan afbrekings op die morfemiese vlak, waar hierdie afbrekings 'n funksie is, nie van besluite nie, maar van temporale motoriese koördinasie. Dit is juis omdat die lettergreep die basiese fisiologiese eenheid van spraak is.

Spanning, emosionele reaksies en tydsdruk ens., sal dus die opeenvolging van spraak verbreek op die mees basiese vlak van integrasie - die morfemiese vlak, of meer spesifiek, lettergreepvlak. Emosionele druk sal die asempols versteur sodat tydsberekening vir die uiting van lettergrepe sal skade ly.

Hierdie onderbrekings op die lettergreepvlak word waarskynlik deur meeste outoriteite as woordonderbrekings gesien, omdat dit die vloei en selfs kommunikasie van die woord aantas. Ons kan egter net weer eens verwys na die stelling dat woorddeel onvlothede die vinnigste as hakkel gediagnoseer word.

Op enige wetenskaplike gebied word gereeld verklarings gemaak en verduidelikings gelewer i.v.m. waarneembare gebeurtenisse. Hierdie verduidelikings word gegrond op 'n verwysingsraamwerk. Op die gebied van hakkel is daar egter twee faktore wat verduideliking en verklaring strem.

1, 'n Massa navorsing i.v.m. sekere fasette van hakkel vertroebel en strem ons siening van die geheelbeeld.

2. Omdat die aanvang en oorsprong van hakkel nie tot dusver vasgepen kon word nie, is navorsers geneig om daarvan weg te skram en hulle eerder toe te lê op die aangebode simptomatologiese beeld wat hom makliker tot verklaring leen.

Die formulering van verduidelikings het egter al dikwels as stimulus tot eksperimentering gelei. Miskien kan hierdie hipotese tog bydra tot ' $n$ beter insig in die probleem van hakkel as 'n geheel:

Hakkel ontstaan as gevolg van 'n biologiese onvermoë om op die morfemiese vlak motoriese patrone temporaal te bemeester. As gevolg van hierdie disorganisasie in spraak, word verskeie ander gedragsvorms omvorm en aangeleer in 'n poging tot aanpassing en kompensasie.

Dit volg noodwendig dat waar 'n teoretiese oriëntasie soveel as moontlik verwys na die totaliteit van 'n probleem, die behandeling wat daarop geskoei is, omvattender sal wees en dus 'n groter kans sal hê op sukses.

\section{BIBLIOGRAFIE}

1. Barbara, D.A. (1965): Stuttering: A Psychodynamic Approach to its 
understanding and Treatment. Thomas, Springfield, 11l, U.S.A.

2. Beech, H.R. and Fransella, F. (1968): Research and Experiment in Stuttering. Pergamon Press. Oxford.

3. Besozzi, T.E. and Adams, M.R. (1969): The Influence of Prosody on Stuttering Adaptation. J. Speech and Hearing Research, 12, 818-824.

4. Black, J.W. (1951): The Effects of Delayed Side-tone upon Vocal Rate and Intensity. J. Speech and Hearing Disorders, 16, 56-60.

5. Bloodstein, O. (1950): Hypothetic Conditions under which stuttering is reduced or absent. J. Speech and Hearing Disorders, 15, 142-153.

6. Bluemel, C.S. (1935): Stammering and Allied Disorders. Macmillan, N.Y.

7. Brutten, E.J. en Shoemaker, D.J. (1967): The Modification of Stuttering. Prentice-Hall Inc. N.Y.

8. Freund, H. (1966): Psychopathology and the Problems of Stuttering. Thomas, Springfield, Ill.

9. Freund, H. (1952): Studies in the Interrelationship between Stuttering and Cluttering. Folia Phoniatrica, 4, 146-168.

10. Lenneberg, E.H. (1967): Biological Foundations of Language. J. Wiley and Sons Inc., N.Y.

11. Luria, A.R. (1966): Higher Cortical Functions in Man. Tavistock. London.

12. Sheehan, J. (1958): Conflict Theory of Stuttering, in Stuttering: a Symposium, J. Eisenson, Ed., Harper, N.Y.

13. Stromsta, C. (1959): Experimental Blockage of Phonation by Distorted Side-tone. J. Speech and Hearing Research, 2, 286-301.

14. Van Riper, C. (1971): The Nature of Stuttering. Prentice-Hall Inc., N.Y.

15. Van Riper, C. (1972): Speech Correction. 5th edition. Prentice-Hall Inc., N.Y.

16. Weiss, D.A. (1964): Cluttering. Prentice-Hall Inc., N.Y:

17. Wischner, G.J. (1950): Stuttering Behavior and Learning. J. Speech and Hearing Disorders, 15, 324-335. 